\title{
Analisis kinerja pada perawat RSUD Tipe C di Propinsi Riau
}

\author{
ARHIPEN YAPENTRA \\ Dosen tetap Sekolah Tinggi Ilmu Ekonomi Riau
}

\begin{abstract}
Abstrak: The purpose of this study was to determine the effect of leadership on nurse motivation, the influence of organizational culture on nurse work motivation, Influence of leadership on nurse performance, the influence of organizational culture on the performance of nurse and The influence of motivation on the nurses performance on RSUD type C in the province of Riau. Type of research was selected is quantitative survey approach. The data used is primary data that collected from 79 nurses at two hospitals from two counties. Secondary data obtained from the author profile data Riau Health Service and source data from both hospitals. Data were analyzed using path analysis technique (Path Analysis). Based on the results of the study concluded that: 1) Leadership is not a significant effect on the motivation of nurses working with the calculation of a score of 0.154 . and sig 0,104 2) Cultural organizations have a significant effect on the motivation of nurses working at 0.665 and sig 0,000 . 3) Leadership is significant effect on the performance of nurses at 0,265 and sig 0,008 4) Cultural organizations have a significant effect on the performance of Nurses at 0.329 and sig 0,009. 5) Motivation significant effect on the performance of Nurses at 0,273 . 6) Indirect effect $X_{1}$ on $Y$ through $X_{3}$ for $\rho \times 3 \times 1$. $\rho \mathrm{yx}_{3}=$ $(0.154)$. $(0.273)=0.042$. So that the total effect of $\mathrm{X} 1$ on $Y$ through $X_{3}$ is equal to 0.042 , and 7 ) Indirect effect $\mathrm{X}_{2}$ on $\mathrm{Y}$ through $\mathrm{X} 3$ for $\rho \mathrm{x}_{3} \mathrm{X}_{2}$. $\rho \mathrm{yx}_{3}=(0.665)$. $(0.237)=0.182$. Total effect on $\mathrm{Y}$ through $\mathrm{X}_{3} \mathrm{X}_{2}$ is equal to 0.182
\end{abstract}

Keywords : Performance, Leadership, Organizational Culture, and Work Motivation

\section{PENDAHULUAN}

Setiap organisasi atau sebuah perusahaan didirikan sudah dapat dipastikan didirikan untuk masa yang panjang atau untuk kurun waktu yang tak berbatas. Maka untuk tetap eksisnya sebuah organisasi harus didukung oleh aktifitas dan perilaku positif para pendiri organisasi kemudian dilanjutkan oleh anggota atau karyawan organisasi tersebut. Aktifitas atau perilaku nyata yang ditampilkan oleh setiap orang merupakan prestasi kerja yang dihasilkan oleh karyawan sesuai dengan perannya dalam perusahaan (HM. Yani, 2012 : 117). Dalam beberapa penelitan dan pengertian para pakar menyebutkan bahwa yang dimaksud dengan prestasi kerja adalah kinerja karyawan (Wibowo, $2011: 8$ ).

Kinerja adalah hasil kerja atau prestasi kerja tentunya banyak faktor yang memengaruhinya. Menurut Robbins (2008 : 281), kinerja adalah seperti sebuah fungsi $(f)$ dari interaksi kemampuan $(\mathrm{A})$ dengan motivasi $(\mathrm{M})$ maka Kinerja $=f(\mathrm{~A} \times \mathrm{M})$. Apabila salah satu dari kedua hal tersebut tidak memadai, maka kinerja akan dipengaruhi secara negatif. Menurut Yuwono dkk, dan Ruky dalam Hessel (2007 : 180), di antara Faktor-faktor yang dominan mempengaruhi kinerja suatu organisasi adalah budaya organisasi dan faktor kepemimpinan yang efektif. Sedangkan Grifin (2004 : 53) menyebutkan bahwa motivasi, faktor kepemimpinan, komunikasi dan proses kelompok adalah faktor yang sangat penting untuk membantu menajer meningkatkan efisiensi dan efektifitas karyawan. 
Faktor lain yang mempengaruhi kinerja organisasi adalah kepuasan kerja karyawan. Menurut Hessel (2007 : 164), tingkat kepuasan kerja adalah salah satu faktor yang mempengaruhi prestasi kerja karyawan yang pada akhirnya akan berpengaruh pada efektifitas organisasi. Kepuasan kerja bukan sekedar memberikan insentif, tapi karyawan juga membutuhkan motivasi, pengakuan atas hasil kerja, suasana kerja yang tidak monoton, adanya peluang untuk berinisiatif dan berkreasi.

Terpenuhinya kepuasan kerja karyawan sebagai pelanggan internal akan berdampak pada loyalitas dan komitmen kerja yang positif selanjutnya akan menghasilkan kinerja yang positif sehingga akan memberikan kepuasan kepada pelanggan ekternal organisasi. Konsep ini sesuai dengan artikel Corporate Leadership Council dalam Ayu Desi Indrawati (2013 : 140), dalam risetnya menyebutkan bahwa persepsi dan kepuasan kerja berkorelasi dengan kepuasan pelanggan. Sehingga ketika konsumen internal (karyawan) merasa senang/terpuaskan, maka mereka akan memperlakukan konsumen eksternal dengan baik. Kondisi tersebut memberikan arti yang sangat penting bagi kelanjutan dan eksistensi organisasi, terlebih lagi bagi organisasi/perusahaan jasa seperti lembaga pendidikan dan rumah sakit.

Rumah sakit baik milik pemerintah maupun swasta adalah suatu organisasi atau badan yang bergerak di bidang pelayanan kesehatan kepada seluruh lapisan masyarakat dengan tidak mengenal diskriminasi. Berdasarkan undang-undang No. 44 Tahun 2009 disebutkan bahwa rumah sakit adalah institusi pelayanan kesehatan yang menyelenggarakan pelayanan kesehatan perorangan secara paripurna yang menyediakan pelayanan rawat inap, rawat jalan, dan gawat darurat. Selain itu rumah sakit juga merupakan pusat pelatihan bagi tenaga kesehatan dan pusat penelitian medik.

Propinsi Riau memiliki luas wilayah 8.915.016 hektar dengan jumlah penduduk berdasarkan sensus penduduk tahun 2010 sebanyak 5.538.367 jiwa dan tingkat pertumbuhan penduduk 3,12\% pertahun (Sumber data : BPS Riau.go.id). Propinsi ini terbagi atas 12 pemerintah daerah kota/ kabupaten, memiliki rumah sakit sebanyak 55 buah, 17 diantaranya adalah milik pemerintah bahwa hingga tahun 2013 terdapat 17 buah Rumah Sakit pemerintah yang ada di propinsi Riau. 12 rumah sakit diantaranya ( 70,6 \%) termasuk rumah sakit dengan tipe C. Satu rumah sakit yang termasuk dalam tipe A dan sisanya klasisfikasi tipe B dan D masing-masing sebanyak dua buah. Artinya lebih dari 5,5 juta Masyarakat Riau 70,6 \% umumnya dilayani Rumah sakit tipe $\mathrm{C}$ tersebut.

Adapun jumlah tenaga kesehatan sebagai sumber daya manusia yang menjalankan roda organisasi rumah sakit di propinsi Riau juga dapat dilihat pada tabel di atas, bahwa perawat adalah tenaga kerja yang lebih dominan di setiap rumah sakit. Jumlah rata-ratanya hingga mencapai $54 \%$ dari keseluruhan tenaga kesehatan di rumah sakit. Dominannya tenaga keperawatan di rumah sakit dapat sangat jelas terlihat, karena hampir setiap ruangan di rumah sakit ditempatkan tenaga perawat untuk merawat setiap pasien yang ada. Dengan jumlah dan penyebarannya yang dominan di rumah sakit, maka tenaga perawat merupakan tenaga kerja yang paling banyak intensitasnya dalam berinteraksi dengan masyarakat yang membutuhkan pelayanan kesehatan. Sehingga perawat dapat dikelompok-kan sebagai karyawan kontak dalam sebuah perusahaan dan kinerjanya akan mempengaruhi kepuasan pasien dan kinerja rumah sakit secara keseluruhan.

Sepantasnya perbedaan klasifikasi rumah sakit bukan menjadi perbedaan standar kualitas pelayanan yang diberikan kepada pasien. Sebagaimana disebutkan pada pasal 5 Peraturan Menteri Kesehatan RI No. 340 tahun 2010 bahwa ketentuan klasifikasi rumah sakit hanya menentukan jumlah fasilitas minimal yang harus tersedia di rumah sakit. Baik fasilitas sumber 
daya manusia, fasilitas sarana dan prasarana, maupun jumlah atau bentuk pelayanan yang tersedia. Adapun yang dimaksud dengan pelayanan pada pasal 5 Peraturan Menteri Kesehatan tersebut dijelaskan dalam pasal 6 sampai pasal 22.

Fenomena yang terjadi dewasa ini, bahwa kualitas pelayanan di rumah sakit pemerintah sering kali tidak memuaskan masyarakat atau pasien pada khususnya. Adanya pasien yang tidak dilayani dengan baik dan ramah, pasien yang ditelantarkan hingga pasien yang dibuang dan meninggal seperti pasien di salah satu rumah sakit di Bandar lampung. (http://health.okezone.com, 2014) atau pasien berusia 9 tahun dalam keadaan kritis yang ditelantarkan lebih dari tiga jam di RSUD Selasih Pangkalan Kerinci,(http://www.riauterkini.com, 2014) dan banyak lagi kasus lainnya baik yang terekspose di media maupun yang tidak terekspos.

Survey awal yang penulis di RSUD Bangkinang 3 dari 10 orang pasien menyatakan tidak puas dengan pelayan tenaga kesehatan. Fakta ini juga diperkuat dalam sebuah berita on line yang mengungkapkan 23 keluhan dari beberapa pasien/pengunjung RSUD Bangkinang disebabkan mereka jarang mendapatkan pelayanan yang ramah misalnya sapaan dengan senyuman dari tenaga medis yang melayani, hingga adanya keluhan pasien terhadap tenaga bidan, perawat dan dokter spesialis yang tidak ada di ruang pelayanan/konsul. (Suara Kampar.com, 01 Oktober 2013). Realita rendahnya perhatian dan kualitas pelayanan tersebut semakin terasa, pada rumah sakit yang merawat pasien di kelas III yang umumnya adalah dari keluarga miskin (GAKIN) dengan fasilitas layanan dari Askes ataupun Jamkesmas/Jamkesda atau yang akhir-akhir ini disatukan dalam satu badan oleh pemerintah yang disebut BPJS.

Realita lain, seringkali kita mendengar atau membaca berita penolakan petugas rumah sakit milik pemerintah untuk merawat pasien dengan alasan tidak ada ruangan atau tempat tidur kosong, sementara dari table 1.1 di atas terlihat angka Turn Over Interval (TOI) RSUD pemerintah di propinsi Riau rata-rata 4 hingga 9 hari. Turn Over Interval (TOI) adalah salah satu faktor indikator kinerja rumah sakit, yaitu jumlah hari tempat tidur tidak terpakai oleh pasien, sedangkan angka idealnya adalah satu hingga tiga hari. Dengan demikian dapat disimpulkan bahwa sebenarnya ada rentang waktu rata-rata 4 sampai 9 hari tempat tidur di rumah sakit tidak ditempati pasien.

Budaya kerja pegawai negeri sipil (PNS) sampai saat ini masih menjadi sorotan masyarakat, terutama terkait dengan aspek perilaku, dan etika moralitas. PNS sering dianggap sebagai pekerja yang bekerja hanya sekedar datang ke kantor, duduk-duduk mengobrol ataupun membaca koran, kemudian pulang dan awal bulan menerima gaji. (Moeheriono, 2012 : 366). Kondisi tersebut di tambah dengan ketersediaan sumber daya alam yang melimpah di propinsi Riau berdampak kurang menumbuhkan motivasi kerja masyarakat umumnya tidak terkecuali tenaga kerja di rumah sakit pemerintah. Dalam bahasa atau jargonan masyarakat setempat disebutkan "Kojo sibu tak kojo limo atui, kojo tak kojo sibu limo atui" (bekerja menerima gaji seribu tidak bekerja menerima gaji lima ratus, kalau kerja tak kerja menerima gaji seribu lima ratus). Sehingga dipahami dengan cara kerja bermalas-malasan (kojo tak kojo) justru mendapatkan penghasilan atau nilai yang lebih besar. Hal ini dikuatkan dengan penelitian yang dilakukan oleh para pakar antropologi seperti Cortesau, Rafles, Wheeler dan Swift yang dikutip oleh Ivanlana berkesimpulan bahwa orang melayu dulunya adalah pemalas. Banyak yang memiliki tanah, supaya dapat hidup senang dan sejahtera, tanpa bekerja keras. (http://vanvanlana.blogspot.com/2011). Sikap tidak disiplin dan malas tersebut semakin diperkuat dengan tertanamnya rasa ego pada sebagian pegawai yang merasa dekat dengan 
pejabat tertentu atau bahkan menjadi pegawai di rumah sakit tersebut merupakan pegawai titipan dari seorang pejabat tertentu (Netty Mindrayani, 2012)

Berkaitan dengan konsep kinerja perawat dijelaskan bahwa perawat adalah bagian dari sumber daya manusia atau karyawan di suatu rumah sakit ataupun institusi pelayanan kesehatan lainnya dengan jumlah yang biasanya jauh lebih banyak dari tenaga kesehatan lainnya. Penjelasan teoritis tentang pengertian perawat dalam penulisan ini, penulis lebih menggunakan kata perawat sebagai karyawan

Wibowo (2011 : 7) menyebutkan bahwa kinerja berasal dari kata performance yang berarti sebagai hasil kerja atau prestasi kerja. Menurut Prawirosentono (2008: 1) performance adalah hasil kerja yang dapat dicapai oleh seseorang atau sekelompok orang dalam suatu organisasi, sesuai dengan wewenang dan tanggung jawabnya masing-masing, dalam rangka upaya mencapai tujuan organisasi bersangkutan secara legal, tidak melanggar hukum dan sesuai dengan moral maupun etika.

Amstrong dan Barong dalam Wibowo (2011 : 7) mendefinisikan bahwa kinerja adalah hasil pekerjaan yang mempunyai hubungan kuat dengan tujuan strategis organisasi, kepuasan konsumen dan memberikan kontribusi pada ekonomi. Dengan demikian, maka kinerja adalah tentang bagaimana melakukan perkerjaan dan hasil yang dicapai dari pekerjaan tersebut. Kinerja juga adalah perilaku nyata yang ditampilkan oleh setiap orang sebagai prestasi kerja hasil yang dihasilkan oleh karyawan sesuai dengan perannya dalam perusahaan (HM. Yani, 2012 : 117).

Menurut Robbins (2008 : 281), kinerja adalah seperti sebuah fungsi $(f)$ dari interaksi kemampuan (A) dengan motivasi $(\mathrm{M})$ maka Kinerja $=f(\mathrm{~A} \times \mathrm{M})$. Apabila salah satu dari keduanya tidak memadai, kinerja akan dipengaruhi secara negatif.

Untuk melihat atau mengukur kinerja karyawan tentunya melalui suatu evaluasi kinerja yang sesuai dengan standar kerja yang telah ditetapkan sebelumnya. Terkait dengan perawat di rumah sakit, evaluasi kerja menurut Nursalam (2009 : 513) memberikan manfaat sebagai berikut: Meningkatkan prestasi kerja staf, baik secara individu dan kelompok, dengan memberikan kesempatan kepada mereka untuk memenuhi kebutuhan aktualisasi diri dalam kerangka pencapaian tujuan pelayanan rumah sakit; Peningkatan yang terjadi pada prestasi staf secara perorangan pada gilirannya akan mempengaruhi atau mendorong SDM secara keseluruhannya; Merangsang minat dalam pengembangan pribadi dengan tujuan meningkatkan hasil karya dan prestasi, dengan cara memberikan umpan balik kepada mereka tentang prestasinya; Membantu rumah sakit untuk dapat menyusun program pengembangan dan pelatihan staf yang lebih tepat guna, sehingga rumah sakit akan mempunyai tenaga yang cakap dan terampil untuk pengembangan pelayanan keperawatan di masa depan; Menyediakan alat dan sarana untuk membandingkan prestasi kerja dengan meningkatkan gaji atau sistem imbalan yang baik; Memberikan kesempatan kepada pegawai atau staf untuk mengeluarkan perasaannya tentang pekerjaannya, atau hal lain yang ada kaitannya melalui jalur komunikasi dan dialog, sehingga dapat mempererat hubungan antara atasan dengan bawahan.

Menurut Sujoko Efferin dan Bonnie Soeherman (2010 : 86) dimensi kinerja merupakan tahap paling kritis. Tujuan dan ukuran yang dikembangkan nantinya akan membentuk pola pikir karyawan tentang apa yang penting dan tidak, sehingga kesalahan penentuan dimensi kerja akan mendorong karyawan untuk meraih sesuatu yang sebenarnya tidak diinginkan organisasi. Profitabilitas, loyalitas pelanggan, inovasi dan produktivitas merupakan contoh dari dimensi kerja. Pada umumya yang sering digunakan sebagai dimensi dalam konteks jasa adalah : Kompetensi, keandalan, tanggung jawab dan empati. (Darmadi Durianto dkk, 2004 : 100) 
Kinerja perawat adalah hasil pekerjaan yang mempunyai hubungan kuat dengan tujuan strategis rumah sakit, kepuasan pasien dan memberikan kontribusi pada ekonomi Menurut Surya Dharma (2004: 514)

Menurut Yuwono dkk (2002 : 53) Faktor-faktor yang dominan mempengaruhi kinerja suatu organisasi meliputi upaya menajemen dalam menerjemahkan dan menyelaraskan tujuan organisasi, budaya organisasi, kualitas sumber daya manusia yang dimiliki organisasi dan kepemimpinan yang efektif. Menurut Ruky dalam Hessel Nogi S. Tangkilisan (2007 : 180) mengidentifikasi faktor-faktor yang berpengaruh langsung terhadap tingkat pencapaian kinerja organisasi sebagai berikut :

1) Teknologi, yang meliputi peralatan kerja dan metode kerja yang digunakan untuk menghasilkan produk atau jasa yang dihasilkan oleh organisasi - semakin berkualitas teknologi yang digunakan, maka akan semakin tinggi tingkat kinerja organisasi tersebut ;

2) Kualitas input atau material yang digunakan oleh organisasi ;

3) Kualitas lingkungan fisik yang meliputi keselamatan kerja, penataan ruangan dan kebersihan ;

4) Budaya organisasi sebagai pola tingkah laku dan pola kerja yang ada dalam organisasi yang bersangkutan ;

5) Kepemimpinan sebagai upaya untuk mengendalikan anggota orgasisasi agar bekerja sesuai dengan standar dan tujuan organisasi ;

6) Pengelolaan sumber daya manusia yang meliputi aspek kopensasi, imbalan, promosi dan lain-lainnya.

\section{METODE}

Metode yang penulis gunakan dalam penelitian ini adalah metode survei dengan teknik asosiatif. Sampel dalam penelitian ini adalah tenaga perawat di RSUD Bangkinang yang berjumlah 79 dari 169 orang dan tenaga perawat di RSUD Selasih Kabupaten Pelalawan yang berjumlah 195 orang. Populasi dimaksud diambil secara acak (simple random sampling). Pengumpulan data dengan menggunakan angket dan data dianalisis dengan analisis jalur.

\section{HASIL}

Kinerja perawat adalah hasil pekerjaan yang mempunyai hubungan kuat dengan tujuan strategis rumah sakit, kepuasan pasien dan memberikan kontribusi pada ekonomi. Konsep tersebut meliputi beberapa dimensi yaitu: kualitas yang meliputi ; akurasi, ketelitian, penampilan, penerimaan dan keluaran. Kuantitas, meliputi ; volume keluaran dan kontribusi, kemudian supervisi yang meliputi ; membutuhkan saran, arahan dan perbaikan. Selanjutnya adalah dimensi kehadiran, meliputi ; regularitas, dapat dipercayai/diandalkan dan ketepatan waktu, dan konservasi, yang meliputi: pencegahan pemborosan, kerusakan dan pemeliharaan peralatan organisasi.

Berdasarkan hasil analisis jalur dapat diketahui hasil penelitian sebagai berikut: 


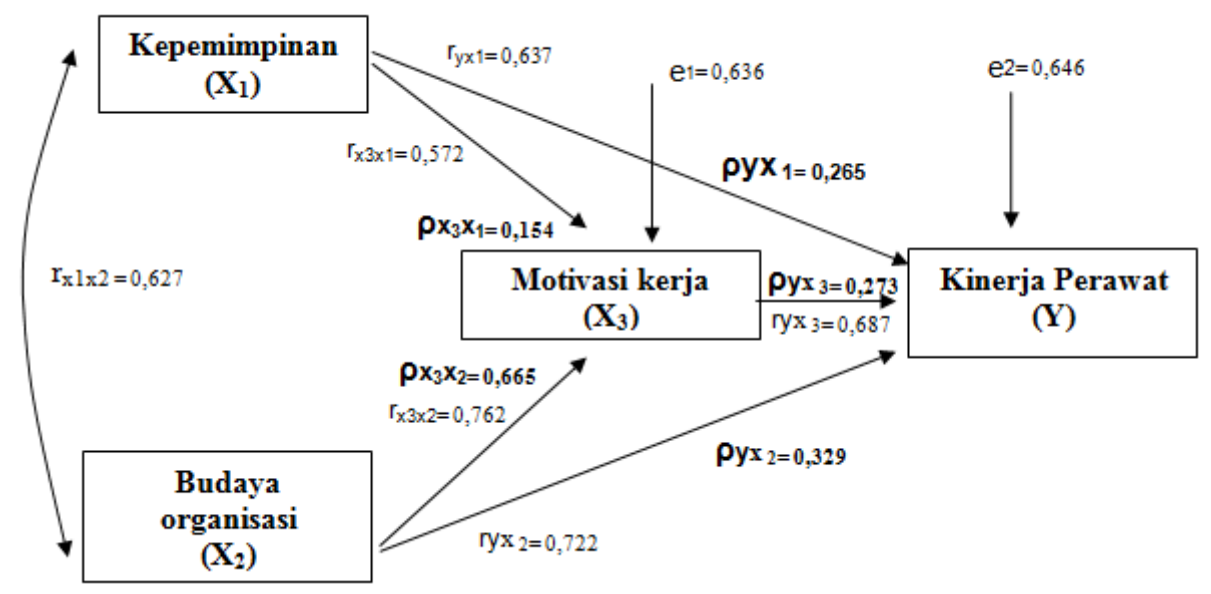

Hasil dari koefisien jalur pada sub-struktur 1 dan sub-struktur 2 berubah menjadi persamaan struktur yaitu:

$$
\begin{aligned}
& X_{3}=\rho \mathrm{x}_{3} \mathrm{x}_{1} \mathrm{X}_{1}+\rho \mathrm{x}_{3} \mathrm{x}_{2} \mathrm{X}_{2}+\rho \mathrm{x}_{3} \mathrm{e}_{1} \text { dan } R^{2} \mathrm{X}_{3,} \mathrm{X}_{2}, \mathrm{X}_{1} \\
& =0,154 \mathrm{X}_{1}+0,665 \mathrm{X}_{2}+0595 \mathrm{e}_{1} \text { dan } 0,636 \\
& \mathrm{Y}=\rho \mathrm{yx}_{1} \mathrm{X}_{1}+\rho \mathrm{yx}_{2} \mathrm{X}_{2}+\rho \mathrm{yx}_{3} \mathrm{X}_{3}+\rho \mathrm{y}_{\mathrm{e} 2} \text { dan } R^{2} \mathrm{y} \mathrm{X}_{3}, \mathrm{X}_{2}, \mathrm{X}_{1} \\
& =0,265 \mathrm{X}_{1}+0,329 \mathrm{X}_{2}+0,273 \mathrm{X}_{3}+0,583 \text { dan } 0,646
\end{aligned}
$$

\section{PEMBAHASAN}

Pengaruh kepemimpinan terhadap motivasi kerja perawat RSUD tipe C di propinsi Riau

Korelasi jawaban kuesioner dari variabel kepemimpinan dan motivasi kerja diatas dapat disimpulkan bahwa penyebab tidak siginifikannya pengaruh kepemimpinan terhadap motivasi kerja perawat adalah konsep kerja pemimpin yang idealis, jauh memandang untuk masa yang akan datang, mewujudkan visi rumah sakit, sementara sisi sudut pandang perawat cenderung realistis dan pragmatis yaitu untuk memenuhi kebutuhan dan kesejahteraan hidupnya. Sehingga ada ketidaksamaan sudut pandang atau motivasi yang mendasari harapan pimpinan dengan yang menjadi harapan karyawan.

Implikasi dari hasil penelitian ini adalah, bahwa kepemimpinan dapat signifikan mempengaruhi motivasi kerja perawat dengan cara pemimpin harus lebih berusaha untuk memahami motivasi yang dominan mempengaruhi kerja perawat, dan mensosialisasikan secara bijaksana visi rumah sakit kepada seluruh karyawan rumah sakit . Hal tersebut dapat dilakukan dengan adanya komunikasi yang baik dan keterbukaan terhadap setiap karyawan. Di sisi lain, 
karyawan juga diharapkan berperan aktif untuk memahami dan memiliki rasa tanggungjawab untuk mewujudkan visi rumah sakit yang telah ditetapkan.

Pengaruh budaya organisasi terhadap motivasi kerja perawat RSUD tipe C di propinsi Riau

Korelasi jawaban pada variabel budaya organisasi dengan variabel motivasi kerja dapat penulis simpulkan bahwa untuk tetap bisa menjadi karyawan dan memperoleh kompensasi sebagai sumber penghasilan utama maka setiap perawat melaksanakan tugas sesuai dengan SOP yang telah ditentukan. Pelanggaran atau penyimpangan terhadap SOP bisa saja berakibat fatal pada pasien dan dampaknya adalah pada karier atau status kepegawaian.

Implikasi dari penelitian ini merekomendasikan bahwa untuk meningkatkan motivasi kerja perawat adalah dengan memaksimalkan budaya organisasi khususnya budaya kerja. Mengunakan peralatan kerja mengikuti ketentuan sebagaimana diatur dalam SOP. Untuk itu perlu dibuat atau diperbaiki dan disepakati bersama SOP terkait dengan semua aktifitas kerja di rumah sakit, seperti cara menyambut dan menyapa pasien atau pengunjung rumah sakit, cara menerima dan mencatat pendaftaran pasien, cara melayani pasien gawat darurat, cara memberikan atau menggunakan peralatan medis pada pasien dan lain sebagainya. Berawal dari budaya mengikuti ketentuan yang diatur dalam SOP dalam berkerja diharapkan akan menjadi kebiasaan dan pada akhirnya akan menjadi budaya kerja atau budaya organisasi.

Pengaruh kepemimpinan terhadap kinerja perawat RSUD tipe C di propinsi Riau

Jawaban tertinggi responden terhadap kuesioner kepemimpinan adalah sebagaimana telah penulis sebutkan sebelumnya, pada item "Pemimpin memiliki arah yang jelas untuk mencapai visi rumah sakit" dengan skor 4,41 dan TCR $88 \%$, kemudian pada item "Pemimpin bisa diajak berdialog dan memberikan solusi dari setiap permasalahan" skor 4,41 dan TCR 88\%. Adapun jawaban tertinggi responden untuk variabel kinerja adalah pada item "kami melayani pasien dengan baik dan ramah" dengan skor 3,34 dan TCR 67\%.

Korelasi jawaban kuesioner variabel kepemimpinan pada variabel kinerja menunjukkan bahwa sikap pimpinan yang menempatkan visi rumah sakit sebagai suatu hal yang harus dicapai dan sikap pimpinan yang bisa diajak berdialog dan memberikan solusi dari persoalan mampu menjadikan perawat bersikap ramah kepada pasien dan berdampak signifikan pada kinerja perawat. Namun dari skor dan TCR yang diperoleh untuk item ini 67\% kategori baik dengan hanya melebihi 7 poin dari kategori cukup, namun item ini tetap bisa menjadi kekuatan untuk meningkatkan variabel kinerja saat ini dengan total skor 3,09 dan TCR 62\%.

Implikasi dari penelitian ini, penulis merekomendasikan agar pimpinan dan segenap karyawan agar lebih meningkatkan sikap ramah pada pasien dan pengunjung secara umum untuk memberikan kenyamanan dan kepuasan pada pengunjung dan meningkatkan kinerja karyawan khususnya dan rumah sakit secara institusional.

Pengaruh budaya organisasi terhadap kinerja perawat RSUD tipe C di Propinsi Riau

Korelasi jawaban kuesioner budaya organisasi dengan variabel kinerja perawat pada item tersebut diatas mengindikasikan bahwa perawat melaksanakan SOP tentang menyambut dan melayani pasien diantaranya adalah untuk bersikap baik dan ramah kepada pasien. Sikap perawat yang mengikuti ketentuan SOP ini mampu mempengaruhi variabel kinerja secara signifikan.

Implikasi dari penelitian ini menjelaskan bahwa untuk meningkatkan kinerja perawat pimpinan rumah sakit perlu menjaga keberlanjutan budaya organisasi yang baik yang telah ada 
dan menciptakan atau membiasakan budaya baru yang positif dengan menetapkan setiap aktifitas kerja dalam satu aturan Standar Operisional Prosedur (SOP).

Pengaruh motivasi kerja terhadap kinerja perawat RSUD tipe C di Propinsi Riau

Korelasi jawaban dari kuesioner motivasi dengan item kuesioner variabel kinerja dapat disimpulkan bahwa adanya dorongan untuk tetap mendapatkan konpensasi dan kesejahteraan kehidupan mempengaruhi kinerja perawat dalam bentuk memberikan pelayanan yang baik dengan berlaku ramah kepada setiap pasien. Namun dari keseluruhan varibel perlu diupayakan peningkatan nilai skor untuk mencapai kinerja yang lebih baik lagi melalui menerapkan hal-hal positif yang tertuang sebagai instrument indikator variable.

Total skor variabel kinerja hasil pengolahan data penelitian adalah 3,09 atau $62 \%$, artinya masih banyak rentang peluang untuk melakukan perbaikan dan meningkatkan kinerja meskipun yang ada sudah termasuk dalam kategori baik. Untuk itu unsur pimpinan rumah sakit sekali lagi perlu mengenali dan memperhatikan faktor-faktor yang mempengaruhi motivasi kerja karyawan melalui pendekatan komunikasi dan keterbukaan kepada karyawan umumnya dan para perawat khususnya.

\section{SIMPULAN}

Berdasarkan hasil penelitian dapat diketahui bahwa kepemimpinan tidak signifikan berpengaruh terhadap motivasi kerja perawat, kemudian budaya organisasi berpengaruh signifikan terhadap motivasi kerja perawat; Kepemimpinan berpengaruh signifikan terhadap kinerja Perawat; Budaya organisasi berpengaruh signifikan terhadap kinerja Perawat; Motivasi kerja berpengaruh signifikan terhadap kinerja Perawat; Pengaruh tidak langsung $\mathrm{X}_{1}$ terhadap $\mathrm{Y}$ melalui $X_{3}$ sebesar $\left(\rho x_{3} X_{1}\right)$. $\left(\rho \mathrm{yx}_{3}\right)=(0,154) \cdot(0,273)=0,042$. Dengan demikian pengaruh total $X_{1}$ terhadap $Y$ melalui $X_{3}$ adalah sebesar 0,042. Pengaruh tidak langsung $X_{2}$ terhadap $Y$ melalui $X_{3}$ sebesar $\left(\rho \mathrm{x}_{3} \mathrm{X}_{2}\right) . \quad\left(\rho \mathrm{yx}_{3}\right)=(0,665) .(0,237)=0,938$. Dengan demikian pengaruh total $\mathrm{X}_{2}$ terhadap $\mathrm{Y}$ melalui $\mathrm{X}_{3}$ adalah sebesar 0,182

\section{DAFTAR PUSTAKA}

Ancok, Djamaluddin, 2012, Psikologi Kepemimpinan dan Inovasi, Erlangga, Jakarta

Bahri, Saiful, 2010, “Optimalisasi Kinerja Kepala Sekolah”, Gibon Media Group, Jakarta.

Boone, Louis E. \& David L. Kurtz, "Pengantar Bisnis Kontemporer 1" ed. 11 Salemba Empat, Jakarta.

Dharma, Surya, “Manajemen Kinerja, Falsafah, Teori \& Penerapannya”,

Grifin, Management, Edisi ke-7 Jilid 1, Erlangga, Jakarta, 2004

Hariandja, Marihot tua Efendi, 2007, “Manajemen Sumber daya manusia”, Grasindo, Jakarta, Cet. Ke empat

Hessel Nogi S Tangkilisan, 2007 “Manajemen Publik”, Cet. Ke-2, Grasindo, Jakarta. 
James M. Henslin 2007 , "Sosiologi dengan Pendekatan Membumi", alih bahasa : Kamanto Sunarto, Jakarta, Edisi ke-6, Erlangga,

Luthan, Fred, 2006, "Perilaku Organisasi”, edisi ke-10, Penerjemah Vivin Andhika Yuwono dkk, Penerbit Andhi, Yogyakarta

Fuad, M. dkk, 2006, Pengantar Bisnis, Cet. Ke-5 Gramedia Pustaka Utama, Jakarta

Mangkunegara, Prabu, 2009, “Manajemen Sumber Daya Manusia Perusahaan”, PT. Remaja Rosdakarya, Bandung.

Matondang, MH, 2008, Kepemimpinan, Budaya Orgaisasi dan Manajemen strategik, cet ke 1, Graha Ilmu, Yogyakarta

Moeheriono, 2012, "Pengukuran Kinerja Berbasis Kompetensi”, Edisi Revisi, PT. Rajawali Grafindo, Jakarta

Mulyasa 2006, “Menjadi Kepala Sekolah Profesional”, PT. Remaja Rosdakarya, Bandung.

Naja, H.R Daeng, 2004, “Manajemen Fit \& Proper Test”, Pustaka Widyatama, Jakarta.

Nursalam dan Ferry Efendi, 2009, Pendidikan dalam Keperawatan, Salemba Medika, Jakarta

Nursalam, 2009, "Manajemen Keperawatan, Aplikasi dan praktik Keperawatan Profesional", Edisi ke-2, Salemba Medika, Jakarta.

Pabundu, Tika, 2008. "Budaya organisasi dan Peningkatan Kinerja Perusahaan” Bumi Aksara, Jakarta

Riduwan dan Engkos Ahmad Kuncoro, 2011, Cara Menggunakan fan Memaknai Path Analysis" Cet. Ke-3, Alfabeta, Jakarta

Robbins, Stephen dan Mary Coulter, 2010. “Manajemen”. Ed 10. Erlangga, Jakarta

Robbins, Sthepens, 2008, “Perilaku Organisasi”, Terjemahan Tim Indeks. Garamedia, Jakarta.

Sugiyono, 2008, “Metode Penelitian Kuantitatif, Kualitatif dan $R \& D$ ”, Cetakan ke empat, Alfabeta, Bandung

Sutrisno, Edy. 2009, Manajemen Sumber Daya Manusia”. Ed.1. Jakarta: Kencana Prenada Media Group.

Thoha, Miftah, 2010, “Kepemimpinan Dalam Manajemen”, Jakarta, PT. Rajagrafindo Persada, 
Timpe, A Dale (editor), 2002, "Seri Manajemen Sumber Daya Manusia ; Kinerja", Cet. Ke-5, Elex Mediakomputindo, Jakarta.

Tjiptono, Fandy dan Gregorius Chandra, 2007, "Service Quality \& Satisfaction", Edisi ke 3, Andi, Yogyakarta

Umam, Khaerul, 2010. “Perilaku Organisasi”, CV Pustaka Setia, Bandung

Wibowo, 2011 “Manajemen Kinerja”, : Rajawali Press, Jakarta

Winardi, 2008, Motivasi \& permotivasian dalam manajemen. Jakarta: PT. Rajawali Press.

Yani, HM., 2012, “Manajemen Sumber Daya Manusia”, Mitra Wacana Media, Jakarta 